\title{
A comparison of methods for gene dosage analysis in HMSN type 1
}

\author{
Jayne S Rowland, David E Barton, Graham R Taylor, UK Clinical Molecular Genetics \\ Society HMSN Project Group*
}

^Euan Stronach, Caroline Clark: Scottish Molecular Genetics Consortium Laboratory, Department of Medical Genetics, University of Aberdeen, Aberdeen, UK. Fiona MacDonald, Max Rindl: Molecular Genetics Laboratory, Birmingham Women's Hospital, Birmingham, UK. Maggie Williams, Linda Tyfield: Molecular Genetics Laboratory, Southmead Hospital, Bristol, UK. Patrick Tarpey, Elizabeth Buckridge: Molecular Genetics Laboratory, Addenbrooke's Hospital, Cambridge, UK. Timothy Bishop: ICRF Genetic Epidemiology, St James's University Hospital, Leeds, UK. Rachel Butler, Janet Lewis: Mersey Regional Molecular Genetics Laboratory, Liverpool Women's Hospital, Liverpool, UK. Shu Yau, Elizabeth Green, Vandana Nihalani: South Thames Regional Genetratory, Livo Genetics Centre (East), Guy's Hospital, London, UK. Robert Elles, David Gokhale: North-Western Regional Molecular Genetics Laboratory, St Mary's Hospital, Manchester, UK. Ann Curtis: Molecular Genetics Unit, Claremont Place, Newcastle upon Tyne, UK. Anneke Seller: Molecular Genetics Laboratory, The Churchill Hospital, Oxford, UK. John Harvey, Claudia Wolf: Wessex Regional Genetics Laboratory, Salisbury District Hospital, Salisbury, UK. Diana Curtis: North Trent Molecular Genetics Labora-
tory, Sheffield Children's Hospital, Sheffield, UK.

\begin{abstract}
A number of different approaches are used in diagnostic laboratories to detect the $1.5 \mathrm{Mb}$ duplication at $17 \mathrm{p} 11.2$ seen in approximately $70 \%$ of patients with hereditary motor and sensory neuropathy type 1 (HMSN1). Here we compare the methods used in UK diagnostic laboratories to detect the duplication. Samples referred to participating centres for HMSN testing were collected, randomised, and distributed for testing. One hundred samples were examined using five different methods; each method was tested by two independent laboratories. Identical results were obtained from all laboratories for 44 samples. The remaining samples were classified as duplication positive or duplication negative on the basis of the same result by two or more methods. A total of 95 samples were classified by more than one method, two were withdrawn from the study as the same result was not obtained by two methods, and three are thought to have a duplication smaller than $1.5 \mathrm{Mb}$. Seven of 49 duplications were not detected by methods used to detect the common junction fragment and the use of microsatellites failed to yield a result in four of 95 samples. Sequence tagged site (STS) dosage analysis was found to be the most sensitive of the methods tested, although this method was found to be the most likely to require repeat analysis. Eight samples gave discordant results between the two laboratories testing by the same method. Upon retesting, reasons for the initial incorrect result included processing and typographical errors.

(F Med Genet 2001;38:90-95)
\end{abstract}

Keywords: HMSN; methods; duplication; gene dosage

Correspondence to: Ms Rowland, jrowland@hgmp.mrc.ac.uk or Jayne.Rowland@ gw.sjsuh.northy.nhs.uk

Revised version received 30 November 2000 Accepted for publication 8 December 2000 heterogeneous group of disorders. HMSN type 1 (HMSN1) (MIM 118220) is the most common with an incidence of about 1/2500.
The hereditary motor and sensory neuropathies (HMSN) or Charcot-Marie-Tooth disease (CMT) are a clinically and genetically
Approximately $70 \%$ of HMSN1 patients have a tandem duplication of a $1.5 \mathrm{Mb}$ region at $17 \mathrm{p} 11.2$ (HMSN1A). ${ }^{1-3}$ The duplicated region includes the peripheral myelin protein gene-22 (PMP-22) which encodes a component of peripheral nerve myelin. ${ }^{4-7}$ Trisomic overexpression of PMP-22 is thought to be the cause of the neuropathy in this group of patients. The involvement of PMP-22 in HMSN pathogenesis is supported by the finding of point mutations in PMP-22 in patients without a duplication. ${ }^{8}$ Two homologous, low copy number, repeat elements flank the repeated region and are designated distal or proximal CMT1AREPs according to their position. ${ }^{2}$ Duplication and the reciprocal deletion events are thought to arise during meiosis owing to non-sister chromatid exchange between misaligned CMT1A-REP elements. ${ }^{29}$ Although the CMT1A-REPs are approximately $24 \mathrm{~kb}$ in size, a hot spot for recombination exists between an EcoRI site unique to the distal CMT1A-REP and a SacI site unique to the proximal CMT1A-REP. In duplicated cases, the recombinant CMT1A-REP contains both sites producing a disease specific junction fragment of $3.2 \mathrm{~kb}$. The recombination hot spot is further refined to a $1.7 \mathrm{~kb}$ region between the EcoRI site of the distal CMT1A-REP and a unique NsiI site on the proximal CMT1AREP. $^{10}$

The methods used in diagnostic laboratories to detect the $17 \mathrm{p} 11.2$ duplication include quantitative methods and methods to detect rearrangements. The aim of this study was to compare the methods used in UK diagnostic laboratories and to determine the sensitivity and reproducibility of each method.

\section{Methods}

Only methods in routine use in two or more UK diagnostic laboratories were tested. This therefore excluded, for example, pulsed field gel electrophoresis. The following methods were compared: microsatellite analysis, detection of the common junction fragment by Southern blotting, detection of the common junction fragment by polymerase chain reaction (PCR), and dosage analysis of PMP-22 using semi-quantitative fluorescent PCR (STS dosage) with products analysed using either 
Table 1 PCR primer sequences for STS dosage analysis

\begin{tabular}{|c|c|c|}
\hline Primer & Sequence ${ }^{\star}\left(5^{\prime}-3^{\prime}\right)$ & $\begin{array}{l}\text { Product size } \\
(b p)\end{array}$ \\
\hline$P M P-22$ Pm1A F & GTC TTG GCA TCA CAG GCT TCA GGC A & 268 \\
\hline$P M P-22$ Pm1A R2 & ACC AGG CTC CCC GAG ATG TTC CCT G & \\
\hline$P M P-22 \mathrm{Ex} 4 \mathrm{~F}$ & CAT CTC AAC TCG GAT TAC TCC TAC G & 374 \\
\hline PMP-22 3'UTR R1 & AGG CTC AAC ACG AGG CTG ATG GTC A & \\
\hline PMP-22 3'UTR F & CTG CTT TTG TAC CTA GCT AGG CTG C & 306 \\
\hline PMP-22 3'UTR R3 & ATG CAT CTT AGT CCA CAC AGT TGG & \\
\hline$P_{o} \operatorname{Ex} 1 \mathrm{~F}$ & CAG TGG ACA CAA AGC CCT CTG TGT A & 389 \\
\hline$P_{o}$ Ex1 R2 & GAC ACC TGA GTC CCA AGA CTC CCA G & \\
\hline$P_{o} \mathrm{Ex} 2 \mathrm{~F}$ & CTC ACT TCC TCT GTA TCC CTT ACT G & 393 \\
\hline$P_{o} \mathrm{Ex} 2 \mathrm{R}$ & GGA GGA CAA TGT AGT CAG GGT GAC A & \\
\hline$P_{o}$ Ex3 F & TGA CAG CTG TGT TCT CAT TAG GGT C & 453 \\
\hline$P$ Ex3 R & TCC GAG TGT ATG CCC TGC ATT GAG G & \\
\hline
\end{tabular}

^Sequences from refs 4, 20-23.

capillary electrophoresis or polyacrylamide gel electrophoresis (PAGE).

SAMPLE DISTRIBUTION

One hundred samples referred to UK Genetics Centres for HMSN testing were collected and comprised approximately 50 samples in which a duplication had been found previously and 50 samples in which a duplication had not been found previously. Patient consent was not sought as the samples had been obtained for the purpose of HMSN testing in the first instance. Samples were classified according to the methods used locally by the contributing laboratories, such as the detection of junction fragments. Consequently, samples in which a duplication had not been detected were not necessarily duplication negative. Several DNA extraction methods had been used by the contributing laboratories, including salting out with ammonium acetate (32 samples) or sodium chloride (10 samples), phenol chloroform extraction (27 samples), and the use of commercial kits, Nucleon (24 samples) (Nucleon Biosciences, UK) and Puregene (seven samples) (Flowgen Instruments, UK). The samples were coded and distributed for testing. Each method was tested independently by two laboratories.

DETECTION OF THE COMMON JUNCTION FRAGMENT BY SOUTHERN BLOT

This method detects the $3.2 \mathrm{~kb} \mathrm{EcoRI/SacI}$ junction fragment specific to duplications. A total of 5-10 $\mu \mathrm{g}$ of genomic DNA was digested with EcoRI and SacI according to the manufacturer's instructions, blotted, and probed. The probe PLR6.0, which corresponds to the 6.0 $\mathrm{kb} E c o$ RI fragment of the distal CMT1A-REP, was used by one laboratory and the probe pNEA102, corresponding to a $1.8 \mathrm{~kb}$ end fragment of PLR6.0, was used by the second. ${ }^{2} 1011$ Both probes detect a $6.0 \mathrm{~kb}$ fragment from the distal CMT1A-REP and a $5.0 \mathrm{~kb}$ fragment from the proximal CMT1A-REP. PLR6.0 also detects a $2.8 \mathrm{~kb}$ fragment from the proximal CMT1A-REP. With both probes HMSN patients have an additional $3.2 \mathrm{~kb}$ junction fragment. Samples were classified as duplicated if the junction fragment was detected or duplication not detected if the junction fragment was absent. For samples in which a duplication had not been detected, analysis of the intensity of the $6.0 \mathrm{~kb}$ and $5.0 \mathrm{~kb}$ bands $^{12}$ was not attempted.
DETECTION OF THE COMMON JUNCTION FRAGMENT BY PCR

A $3.6 \mathrm{~kb}$ region including the EcoRI site of the distal CMT1A-REP was amplified. Long range PCR was carried out using a forward primer complementary to both the proximal and distal CMT1A-REPs and a reverse primer complementary to the proximal CMT1A-REP only. ${ }^{13}$ Sequences from the proximal and recombinant CMT1A-REPs only are amplified. Following restriction enzyme digestion with EcoRI, the recombinant CMT1A-REP, which contains the EcoRI site of the distal CMT1A-REP, is cut into products of $3.2 \mathrm{~kb}$ and $0.4 \mathrm{~kb}$. The proximal CMT1A-REP, which lacks the EcoRI site, remains intact. Samples were classified as duplicated if the junction fragment was detected or duplication not detected if the junction fragment was absent.

MICROSATELLITE ANALYSIS

The microsatellite markers Mfd41 (D17S261), RM11-GT (D17S122), AFM200yb12 (D17S839), AFM317yg1 (D17S955), and AFM191xh12 (D17S921) were used in the study. The order of the microsatellites with respect to $P M P-22$ is cen - Mfd41 - RM11-GT - PMP-22 - AFM200yb12 - AFM317yg1 AFM191xh12 - tel. ${ }^{14-16}$ Amplifications were carried out as previously described. ${ }^{17}{ }^{18}$ PCR products were visualised by silver staining following PAGE in one laboratory. Fluorescently labelled PCR products were detected by the second laboratory using an $\mathrm{AB} \quad 373$ sequence analyser (Applied Biosystems, USA). Samples were classified as duplication detected by the presence of three different alleles with a single marker or by a $2: 1$ dosage ratio between two alleles observed with at least two markers. Samples were classified as duplication not detected if a 1:1 dosage ratio between two alleles was observed with at least two markers. Dosage estimates were subjective in both laboratories. Dosage determination was not always possible if alleles differed by $1 \mathrm{bp}$ or $2 \mathrm{bp}$ owing to interference from stutter bands from the larger allele or if alleles were of substantially differing sizes because of problems of preferential amplification of the smaller sized allele. Such results were scored as non-reportable. A result was scored as uninformative if only one allele was observed.

GENE DOSAGE BY SEMI-QUANTITATIVE PCR (STS DOSAGE)

This method involves direct detection of duplication of $P M P-22$ using semi-quantitative fluorescent multiplex PCR. ${ }^{19}$ Three sequence tagged sites from PMP-22 (Pm1A, exon 4, and 3'UTR) and three exons (exons 1, 2, and 3) from a control gene, myelin protein zero $\left(P_{0}\right)$ on 1q22-23, were coamplified in a fluorescent multiplex PCR. A total of 2-10 pmol of each primer, 100-200 ng of genomic DNA, and 18 PCR cycles were used to ensure the reaction was kept within the exponential phase. The primer sequences are shown in table $1 .^{40-23}$

The products were resolved on either an $\mathrm{AB}$ (Applied Biosystems, USA) 373 or 377 sequence analyser (PAGE) or 310 sequence ana- 
Table 2 Comparison of the results obtained from the two laboratories testing by the same method

\begin{tabular}{lll}
\hline Method & $\begin{array}{l}\text { No of analyses } \\
\text { compared }\end{array}$ & $\begin{array}{l}\text { No of analyses } \\
\text { discordant (\%) }\end{array}$ \\
\hline Junction fragment by Southern blot & 92 & $2(2.2)$ \\
Junction fragment by PCR & 91 & $0(0)$ \\
Microsatellite analysis & 79 & $2(2.5)$ \\
STS dosage with capillary electrophoresis & 89 & $0(0)$ \\
STS dosage with PAGE & 83 & $4(4.8)$ \\
\hline
\end{tabular}

Table 3 Comparison of the results obtained from the five methods

\begin{tabular}{lll}
\hline Method & $\begin{array}{l}\text { No of duplications } \\
\text { missed by both } \\
\text { laboratories (\%) }\end{array}$ & $\begin{array}{l}\text { No of samplest with no } \\
\text { result from both } \\
\text { laboratories (\%) }\end{array}$ \\
\hline Junction fragment by Southern blot & $7(14 \%)$ & 0 \\
Junction fragment by PCR & $8(16 \%)$ & $1(1)$ \\
Microsatellite analysis & $1(2 \%)$ & $4(4.2)$ \\
STS dosage with capillary electrophoresis & $0(0 \%)$ & 0 \\
STS dosage with PAGE & $0(0 \%)$ & 0
\end{tabular}

*Total number of samples classified as duplicated $=49$.

†Total number of samples $=95$.

lyser (capillary electrophoresis) according to the manufacturer's instructions.

The results from the test sample were compared with those from a non-deleted, nonduplicated control sample. Dosage quotients for each STS with each control exon were calculated using peak heights or peak areas, as described previously for dosage analysis of the dystrophin gene. ${ }^{24}$ An example of the dosage quotient for $P M P-22$ exon 4 compared with $P_{0}$ exon 1 is shown.

PMP-22 exon 4 (test sample) $/ P_{0}$ exon 1 (test sample)

PMP-22 exon 4 (control sample)/ $P_{0}$ exon 1 (control sample)

A total of nine dosage quotients were calculated for each test sample. The mean and standard deviation of the nine dosage quotients was calculated and a qualitative result, duplicated or not duplicated, determined. If the standard deviation was greater than $10 \%$ of the mean the test was repeated.

\section{Results}

REPRODUCIBILITY OF METHOD

To test the reproducibility of each method, a comparison was made between the results obtained from the two laboratories testing by the same method. A comparison was therefore only possible if a result was obtained from both laboratories. The number of results compared for each method is shown in table 2. One hundred percent concordance was observed for the detection of junction fragments by PCR and dosage analysis of $P M P-22$ with capillary electrophoresis. Discrepancies were observed with the other three methods. The percentage of discordant results observed was $2.2 \%$ for the detection of junction fragments by Southern blot (two samples), $2.5 \%$ for microsatellite analysis (two samples), and $4.8 \%$ for STS dosage analysis with PAGE (four samples). The correct result for the eight discrepant samples was taken as the consensus result from the other four methods. Laboratories with the discrepant results were asked to retest a blinded series of the original samples that included the samples with the discrepant results. Upon retesting, three of the samples failed to give a result, four samples typed as the consensus result, and one gave the same discrepant result. For the three samples that failed upon retest, it was not possible to determine the cause of the discrepant result. Of the four samples that typed as the consensus result upon retesting, processing errors were given as the cause of the original incorrect result for three samples and one was found to have typed correctly in the first instance but to have been reported incorrectly. One sample retyped with the same discrepant result using dosage analysis with PAGE.

SENSITIVITY OF METHOD

A comparison was made between the results obtained from the different methods in order to test the sensitivity of each method. Identical results were obtained from all 10 laboratories for 44 samples. An additional seven samples were classified as duplication positive by microsatellite analysis and STS dosage methods, but a duplication was not detected by either junction fragment method. For the remaining samples a result was not obtained from one or more laboratories because of either test failure (no result) or the result being uninformative. These samples were classified as duplication positive if evidence for a duplication was seen by two or more methods. Ninety five samples were classified duplication positive or negative. The remaining five samples were withdrawn from the comparison because of indeterminate results (see discussion). To carry out the comparison, a method was scored as having achieved a result if a result was obtained from at least one of the laboratories testing by that method.

Forty nine samples were classified as duplication positive. Dosage analysis of PMP-22 using semi-quantitative fluorescent PCR with either capillary electrophoresis or PAGE detected all the duplications (table 3) and 48/49 (98\%) of duplications were detected by microsatellite analysis. The remaining duplication detected by STS dosage methods was confirmed by methods detecting junction fragments. Microsatellite analysis failed to detect a duplication in this sample as informative results were obtained from only one marker. One laboratory found a 2:1 dosage ratio between alleles with $\mathrm{mfd} 41$. The results from AFM191xh12, AFM200yb12, and AFM317yg 1 were uninformative and the results from RM11GT were deemed nonreportable. Reporting on a single marker would have given the correct result but fell below the internal quality control criteria set by the laboratory. The second laboratory found a normal dosage ratio with RM11GT. The results from AFM191xh12 and AFM200yb12 were uninformative and analysis with $\operatorname{mfd} 41$ failed. Reporting on a single marker in this instance would have led to an incorrect result.

Fourteen percent of duplications were not detected by methods used to detect the common junction fragment. Analysis of one sample failed for both laboratories detecting junction fragments by PCR resulting in $16 \%$ of duplications being undetected. Microsatellite 
Table 4 Number of failed tests and repeat analyses for each method

\begin{tabular}{lll}
\hline Method & $\begin{array}{l}\text { No of failed } \\
\text { tests }\end{array}$ & $\begin{array}{l}\text { No of samples analysed more } \\
\text { than once }\end{array}$ \\
\hline Junction fragment by Southern blot & 10 & 9 \\
Junction fragment by PCR & 13 & 11 \\
Microsatellite analysis & 26 & 27 \\
STS dosage with capillary electrophoresis & 12 & 64 \\
STS dosage with PAGE & 20 & 49 \\
\hline
\end{tabular}

${ }^{\star}$ Total number of failed tests $=81$.

analysis and STS dosage methods detected all of the duplications missed by junction fragment methods.

Forty six samples were classified as duplication negative by junction fragment and STS dosage methods. Microsatellite analysis failed to produce a result for three samples because of either uninformative results or inconsistent results between markers.

TEST FAILURE AND REPEAT ANALYSIS

Out of a total of 1000 tests, 81 failed (that is, null or uninformative results, table 4). Both microsatellite analysis and STS dosage with PAGE had more failures than the other methods.

The number of samples analysed more than once is also shown in table 4 . The number of repeat analyses does not include repeat analysis on samples that ultimately failed. The STS dosage methods required repeat analysis more often than the other methods.

POLYMORPHISM IN PMP-22 EXON 4 AMPLICON For one sample a split peak was observed with the PMP-22 exon 4 amplicon. The two peaks differed in size by $5 \mathrm{bp}$. The amplicon was sequenced (data not shown; EG, personal communication) and the difference found to be the result of a polymorphism in the number of repeats of CAAAC present in the 3'UTR of the gene. The sample was found to be heterozygous for two and three copies of the repeat.

\section{Discussion}

Five methods routinely used in UK diagnostic laboratories to detect the HMSN1A $17 \mathrm{p} 11.2$ duplication have been evaluated on a series of 100 DNA samples. Eight samples had discrepant results between the two laboratories testing by the same method. Where the reason for the discrepancy was determined, it was found to be the result of processing or typographical errors. These errors were therefore the result of problems in carrying out the method and not problems inherent in the method. One sample retyped with the same discrepant result, using STS dosage with PAGE. The reason for this could be a processing error or a problem inherent in the method. Ninety five samples were classified by two or more methods as either duplication positive (49 samples) or duplication negative (46 samples). The remaining five samples had indeterminate results (table 5). Sample 100 had results for microsatellite analysis only (not duplicated). Sample 33 typed as not duplicated by microsatellite analysis with distal and proximal markers, but typed as duplicated by dosage analysis with capillary electrophoresis. These sample were withdrawn from the comparison of methods as they were not classified by two or more methods.

Three samples may have a duplication smaller than $1.5 \mathrm{Mb}^{25}$ Sample 38 typed as duplicated by both STS dosage methods but did not have the common junction fragment by both junction fragment methods. Results from microsatellite analysis were inconsistent; both laboratories found the sample to be duplicated with the proximal marker RM11GT but not duplicated with the distal marker AFM191xh12. This sample could have a duplication that includes RM11GT but does not include AFM191xh12. Sample 1 typed as duplicated by both STS dosage methods but did not have the common junction fragment by both junction fragment methods. Microsatellite analysis found the sample to be not duplicated with the two proximal markers and the most distal marker (AFM191xh12). The closest distal marker to PMP-22 (AFM200yb12) was uninformative. If this sample has a partial duplication then it must occur between RM11-GT and AFM191xh12. Sample 94 typed as duplicated by dosage analysis with capillary electrophoresis and junction fragment detection by Southern blot but typed as not duplicated by microsatellite analysis. This sample was informative for distal microsatellites only. Results were not obtained from the other methods.

One sample, classified as duplicated, was found to have a polymorphism in the PMP-22 exon 4 amplicon. This sample was found to be heterozygous for two and three copies of a $5 \mathrm{bp}$ repeat in the 3'UTR of the gene.

A diagnostic test needs to be relatively easy to perform, have a high detection rate, and not be prone to test failure or uninformative results. The use of methods to detect the common junction fragment detected $86 \%$ of duplications (table 3 ). This is consistent with the detection rate reported in previous studies. Screening for the EcoRI/SacI junction fragment by Southern blot is reported to detect about

Table 5 Summary of samples with indeterminate results

\begin{tabular}{llllll}
\hline & \multicolumn{2}{l}{ Sample No } & & & \\
\cline { 2 - 6 } & 100 & 33 & 38 & 1 & 94 \\
\hline Junction fragment by Southern blot & $\mathrm{F}$ & $\mathrm{F}$ & $\mathrm{N}$ & $\mathrm{N}$ & $\mathrm{D}$ \\
Junction fragment by PCR & $\mathrm{F}$ & $\mathrm{F}$ & $\mathrm{N}$ & $\mathrm{N}$ & $\mathrm{F}$ \\
Microsatellite analysis & $\mathrm{N}$ & $\mathrm{N}$ & $\mathrm{I}$ & $\mathrm{N}$ & $\mathrm{D}$ \\
STS dosage with capillary electrophoresis & $\mathrm{F}$ & $\mathrm{D}$ & $\mathrm{D}$ & $\mathrm{D}$ & $\mathrm{F}$ \\
STS dosage with PAGE & $\mathrm{F}$ & $\mathrm{F}$ & $\mathrm{D}$ & $\mathrm{D}$ \\
Classification & Withdrawn & Withdrawn & Possible partial & Possible partial & Possible partial \\
& & & duplication & duplication & duplication \\
\hline
\end{tabular}

$\mathrm{F}=$ failed. $\mathrm{N}=$ not duplicated $. \mathrm{D}=$ duplicated. $\mathrm{I}=$ inconsistent. 
$80 \%$ of duplications. ${ }^{10}{ }^{12}$ Screening for the same rearrangement by PCR is also reported to detect $80 \%$ of duplications. ${ }^{13}$ The results from the PCR method compare with those from the Southern blot method. PCR may therefore be the method of choice for the detection of junction fragments as it is quicker to perform, needs less DNA, and does not require the use of radioactivity.

Overall, the use of microsatellites failed to yield a result in $4.2 \%$ of classified samples (table 3). Microsatellite analysis often requires several tests in order to obtain an informative result. The failure to obtain a result was because of the results being non-reportable or uninformative as well as failure to amplify DNA from the sample.

The use of STS dosage was the most sensitive method (table 3). Results were obtained from at least one laboratory for all of the classified samples with both PAGE and capillary electrophoresis. However, this approach had a high failure rate and required more repeat analyses than the other methods, perhaps reflecting a greater technical difficulty (table 4). For both methods, the test was repeated if the standard deviation of the dosage quotients was greater than $10 \%$ of the mean. With capillary electrophoresis the sample is resolved through a polymer and the whole sample loading is analysed. With PAGE the sample is resolved through a gel and a reading is taken through a transect of the sample track. The two electrophoresis systems were compared to determine if analysing data from the whole sample is more robust than analysing data through a transect of the sample track where equivalent data points may not be compared owing to gel variation during electrophoresis. This would affect the dosage quotient calculation and increase the standard deviation. A greater number of test failures was observed with PAGE (20 samples) than with capillary electrophoresis (12 samples), which suggests that capillary electrophoresis is more robust than PAGE for the detection of gene dosage abnormalities.

Of the 100 samples tested, 15 failed to give a result in more than one laboratory (data not shown). The samples tested were extracted in several laboratories by a variety of methods (see sample distribution). Fewer failures were observed with DNA extracted using salt purification methods. However, as these samples may also be the most recently extracted, few conclusions can be drawn regarding test failure and extraction method. The failure to obtain a result is either test dependent, sample dependent, or both. For microsatellite analysis, reasons for test failure were mostly test dependent and included uninformative results, informative results from a single marker only, and inconsistent results between microsatellites. A total of 26 test failures were observed with microsatellite analysis, 15 of which were because results were obtained from a single marker only. Had the result been reported it would have been incorrect in 3/15 cases. RM11GT has been found not to give consistent results in quantitative dosage analyses, and in some laboratories it is only used to detect the presence of three alleles (DEB, personal communication) The addition of further microsatellite markers from within the duplicated region may improve the sensitivity of this approach (and make it more likely that three alleles will be observed in duplicated samples), but would also increase the number of tests required to obtain a result. For STS dosage methods the main reason for test failure was poor data which is both test and sample dependent. In addition, poor data resulted in repeat analysis being carried out for several samples which may reflect the performance of the test with poor quality samples.

The advantages and disadvantages of each method are summarised in table 6. The method of choice for detecting the $17 \mathrm{p} 11.2$ duplication will ultimately depend upon the facilities available and the limitations of each test. For the less sensitive methods, the limitations of the test sensitivity should be reported with the results. Patients with hereditary neuropathy with liability to pressure palsies (HNPP) can also be screened with the same molecular genetic techniques to detect the reciprocal $1.5 \mathrm{Mb}$ deletion at $17 \mathrm{p} 11.2-\mathrm{p} 12$. HMSN and HNPP patients that are negative for the duplication/deletion test should be screened for point mutations in the most relevant peripheral myelin protein genes.

In conclusion, this study showed that STS dosage analysis by semi-quantitative PCR was the most sensitive assay for the detection of PMP-22 duplications, but is technically more demanding than the other methods. Alternative gene dosage methods such as array comparative genomic hybridisation (array$\mathrm{CGH})^{26}$ or multiplex amplifiable probe hybridisation $(\mathrm{MAPH})^{27}$ might retain the high sensitivity that we observed in a simpler assay format.

Table 6 Summary of the advantages and disadvantages of each method

\begin{tabular}{|c|c|c|}
\hline Method & Advantages & Disadvantages \\
\hline Junction fragment by Southern blot & Low failure and repeat analysis rate & $\begin{array}{l}\text { Radioisotope used in assay } \\
14 \% \text { of duplications missed }\end{array}$ \\
\hline Junction fragment by PCR & $\begin{array}{l}\text { Rapid } \\
\text { Low failure and repeat analysis rate }\end{array}$ & $14 \%$ of duplications missed \\
\hline Microsatellite analysis & $\begin{array}{l}\text { Samples can be classified as duplicated or } \\
\text { not duplicated }\end{array}$ & $\begin{array}{l}\text { High failure rate } \\
\text { Several tests required } \\
\text { Partial duplications may be missed }\end{array}$ \\
\hline STS dosage with capillary electrophoresis & $\begin{array}{l}\text { Samples classified as duplicated or not } \\
\text { duplicated }\end{array}$ & $\begin{array}{l}\text { Requires expensive equipment } \\
\text { Repeat analysis often necessary }\end{array}$ \\
\hline STS dosage with PAGE & $\begin{array}{l}\text { Samples classified as duplicated or not } \\
\text { duplicated }\end{array}$ & $\begin{array}{l}\text { Requires expensive equipment } \\
\text { Repeat analysis often necessary }\end{array}$ \\
\hline
\end{tabular}


1 Lupski JR, Montes de Oca-Luna R, Slaugenhaupt S, Pentao L, Guzzetta V, Trask BJ, Saucedo-Cardenas O, Barker DF, duplication associated with Charcot-Marie-Tooth disease duplication associated with Cha
type 1A. Cell 1991;66:219-32.

2 Pentao L, Wise CA, Chinault AC, Patel PI, Lupski JR. Charcot-Marie-Tooth type 1A duplication appears to arise from recombination at repeat sequences flanking the 1.5 Mb monomer unit. Nat Genet 1992;2:292-300.

3 Nelis E, van Broeckhoven C, De Jonghe P, Lofgren A, Vandenberghe A, Latour P, Le Guern E, Brice A, Mostacciuolo ML, Schiavon F, Palau F, Bort S, Upadhyaya M, Rocchi M, Archidiacono N, Mandich P, Bellone E, Silander K, Savontaus ML, Navon R, Goldberg-Stern H, Estivill X, Volpini V, Friedl W, Zerres K, Tyson J, Malcolm S, Holmberg B, Holmgren G, Mariman ECM, Gabreels-Festen AAWM, Yapijakis C, Vassilopoulos D, Clark C, Haites N, Hilbert P, Van Maldergem L, Rautenstrauss B, Grehl H, Mountford R, Mann K, Bettecken T, Burgunder JM, Hanemann CO, Muller HW, Hertz JM, Schorderet DF, Kuntzer mann CO, Muller HW, Hertz JM, Schorderet DF, Kuntzer Gal A. Estimation of the mutation frequencies in CharcotGal A. Estimation of the mutation frequencies in CharcotMarie-Tooth disease type 1 and hereditary neuropathy with
liability to pressure palsies: a European collaborative study. liability to pressure palsies: a E

4 Patel PI, Roa BB, Welcher AA, Schoener-Scott R, Trask BJ, Pentao L, Snipes GJ, Garcia CA, Francke U, Shooter EM, Lupski JR, Suter U. The gene for the peripheral myelin protein PMP-22 is a candidate for Charcot-Marie-Tooth disease type 1A. Nat Genet 1992;1:159-65.

5 Valentijn LJ, Bolhuis PA, Zorn I, Hoogendijk JE, van den Bosch N, Hensels GW, Stanton VP Jr, Housman DE, Fischbeck KH, Ross DA, Nicholson GA, Meershoek EJ, Dauwerse HG, van Ommen GJB, Baas F. The peripheral myelin gene PMP-22/GAS-3 is duplicated in CharcotMarie-Tooth disease type 1A. Nat Genet 1992;1:166-70.

6 Timmerman V, Nelis E, van Hul W, Nieuwenhuijsen BW,

Chen KL, Wang S, Ben Othman K, Cullen B, Leach RJ, Hanemann CO, De Jonghe P, Raeymaekers P, van Ommen G-JB, Martin J-J, Muller HW, Vance JM, Fischbeck KH, van Broeckhoven C. The peripheral myelin protein gene van Broeckhoven C. The peripheral myelin protein gene PMP-22 is contained within the Charcot-Marie-To

7 Matsunami N, Smith B, Ballard L, Lensch MW, Robertson M, Albertsen H, Hanemann CO, Muller HW, Bird TD, White R, Chance PF. Peripheral myelin protein-22 gene maps in the duplication in chromosome 17p11.2 associated
with Charcot-Marie-Tooth 1A. Nat Genet 1992;1:176-9.

8 Valentijn LJ, Baas F, Wolterman RA, Hoogendijk JE, van den Bosch NH, Zorn I, Gabreels-Festen AA, de Visser M, Bolhuis PA. Identical point mutations of PMP-22 in Trembler-J mouse and Charcot- Marie-Tooth disease type 1A. Nat Genet $1992 \cdot 2 \cdot 288-91$.

9 Chance PF, Abbas N, Lensch MW, Pentao L, Roa BB, Patel PI, Lupski JR. Two autosomal dominant neuropathies result from reciprocal DNA duplication/deletion of a region on chromosome 17. Hum Mol Genet 1994;3:223-8.

10 Reiter LT, Murakami T, Koeuth T, Pentao L, Muzny DM, Gibbs RA, Lupski JR. A recombination hotspot responsible for two inherited peripheral neuropathies is located near mariner transposon-like element. Nat Genet 1996;12:28897.

11 Lorenzetti D, Pareyson D, Sghirlanzoni A, Roa BB, Abbas NE, Pandolfo M, Di Donato S, Lupski JR. A 1.5-Mb deletion in $17 \mathrm{p} 11.2-\mathrm{p} 12$ is frequently observed in Italian families with hereditary neuropathy with liability to pressure palsies. Am f Hum Genet 1995;56:91-8.

12 Timmerman V, Rautenstrauss B, Reiter LT, Koeuth T, Lofgren A, Liehr T, Nelis E, Bathke KD, De Jonghe P, Greh
H, Martin JJ, Lupski JR, van Broeckhoven C. Detection of the CMT1A/HNPP recombination hotspot in unrelated patients of European descent. $\mathcal{F}$ Med Genet 1997;34:43-9.

13 Stronach EA, Clark C, Bell C, Lofgren A, McKay NG, Timmerman V, van Broeckhoven C, Haites NE. Novel PCR-based diagnostic tools for Charcot-Marie-Tooth type $1 \mathrm{~A}$ and hereditary neuropathy with liability to pressure palsies. F Periph Nerv Syst 1999;4:117-22.

14 Cudrey C, Chevillard C, Le Paslier D, Vignal A, Passage E, Fontes M. Assignment of microsatellite sequences to the region duplicated in CMT1A (17p12): a useful tool for diagnosis. F Med Genet 1995;32:231-3.

15 LeGuern E, Ravise N, Gouider R, Gugenheim M, Lopes J, Bouche P, Agid Y, Brice A. Microsatellite mapping of the deletion in patients with hereditary neuropathy with liability to pressure palsies (HNPP): new molecular tools for the study of the region $17 \mathrm{p} 12 \rightarrow \mathrm{p} 11$ and for diagnosis. Cytogenet Cell Genet 1996;72:20-5.

16 Navon R, Timmerman V, Lofgren A, Liang P, Nelis E, Zeitune $M$, van Broeckhoven C. Prenatal diagnosis of Charcot-Marie-Tooth disease type 1A (CMT1A) using molecular genetic techniques. Prenat Diagn 1995;15:63340.

17 Weber JL, Kwitek AE, May PE, Wallace MR, Collins FS, Ledbetter DH. Dinucleotide repeat polymorphisms at the D17S250 and D17S261 loci. Nucleic Acids Res 1990;18: 4640 .

18 Gyapay G, Morissette J, Vignal A, Dib C, Fizames C, Millasseau P, Marc S, Bernardi G, Lathrop M, Weissenbach J. The 1993-94 Genethon human genetic linkage map. Nat Genet 1994;7:246-339.

19 Yau SC, Mathew CG, Abbs S. A single PCR assay detects CMT1A duplications and HNPP deletions of PMP-22 gene. F Med Genet 1996;33(suppl 1):S3A.

20 Hayasaka K, Himoro M, Nanao K, Sato W, Miura M, Uyemura K, Takahashi E, Takada G. Isolation and sequence determination of cDNA encoding PMP-22 (PAS- II/SR13/ Gas-3) of human peripheral myelin. Biochem Biophys Res Commun 1992:186:827-31. Genbank Accession Number D11428.

21 Suter U, Snipes GJ, Schoener-Scott R, Welcher AA, Pareek S, Lupski JR, Murphy RA, Shooter EM, Patel PI. Regulation of tissue specific expression of alternative peripheral tion of tissue specific expression of alternative peripheral promoters. f Biol Chem 1994;269:25795-808.

22 Pham-Dinh D, Fourbil Y, Blanquet F, Mattei M-G, Roeckel N, Latour P, Chazot G, Vandenberghe A, Dautigny A. The major peripheral myelin protein zero gene: structure and localisation in the cluster of $\mathrm{Fc} \gamma$ receptor genes on human chromosome 1q21.3-q23. Hum Mol Genet 1993;2:2051-4.

23 Hayasaka K, Takada G, Ionasescu VV. Mutation of the myelin Po gene in Charcot-Marie-Tooth neuropathy type 1B. Hum Mol Genet 1993;2:1369-72.

24 Yau SC, Bobrow M, Mathew CG, Abbs SJ. Accurate diagnosis of carriers of deletions and duplications in Duchenne/Becker muscular dystrophy by fluorescent dosage analysis. 7 Med Genet 1996;33:550-8.

25 Valentijn LJ, Baas F, Zorn I, Hensels GW, de Visser M, Bolhuis PA. Alternatively sized duplication in Charcot-MarieTooth disease type 1A. Hum Mol Genet 1993;2:2143-6.

26 Pinkel D, Segraves R, Sudar D, Clark S, Poole I, Kowbel D, Collins C, Kuo WL, Chen C, Zhai Y, Dairkee SH, Ljung BM, Gray JW, Albertson DG. High resolution analysis of DNA copy number variation using comparative genomic hybridization to microarrays. Nat Genet 1998;20:207-11.

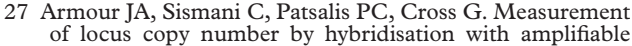
probes. Nucleic Acids Res 2000;28:605-9. 